\title{
Surface Finish Evaluation of AISI P100 Steel after Grinding with MQL Technique with Different Flow Rates
}

Bruno Souza Abrão ${ }^{1}$, Mayara Fernanda Pereira ${ }^{1}$, Cleudes Guimarães ${ }^{1}$, Lurian Souza Vieira da Silva ${ }^{1}$, Rodrigo de Souza Ruzzi ${ }^{1}$, Rosemar Batista da Silva ${ }^{1}$, Eduardo Carlos Bianchi ${ }^{2}$ and Alisson Rocha Machado ${ }^{1,3}$

1. School of Mechanical, Federal University of Uberlandia, Uberlandia/MG, CEP 38.408-208, Brazil

2. School of Engineering, São Paulo State University, Bauru/SP, CEP 17.033-360, Brazil

3. Mechanical Engineering Graduate Program, Pontifícia Universidade Católica do Paraná (PUC-PR), R. Imaculada Conceição, 1155, Bairro Prado Velho, CEP 80215-901, Curitiba/PR, Brazil

\begin{abstract}
Grinding operation is a finishing process often employed when high precision and narrow geometric tolerances are required. These requirements can be achieved only if cutting conditions are properly selected, especially the cooling-lubrication technique. In general, grinding is performed in presence of cutting fluid, however, due to the environmental impacts and costs of the conventional coolant delivery technique (flow rates from $4 \mathrm{~L} / \mathrm{min}$ to $300 \mathrm{~L} / \mathrm{min}$ ), alternative cooling-lubrication techniques have been developed on restriction of the coolants use. Among the several techniques, MQL (minimum quantity of lubricant) technique has received special attention from machining users because of its advantages in terms of surface quality of workpiece and drastic reduction in use of coolant. In this context, this paper evaluated the performance of the MQL technique as compared to the flood coolant in peripheral surface grinding of AISI P100 (VP100) steel with conventional aluminum oxide grinding wheel in relation to the surface roughness ( $\mathrm{Ra}$ and $\mathrm{Rz})$. Input parameters tested were equivalent chip thickness $(0.09 \mu \mathrm{m}, 0.18 \mu \mathrm{m}$ and $0.27 \mu \mathrm{m})$ and flow rate of the cutting fluid $(60 \mathrm{~mL} / \mathrm{h}, 150 \mathrm{~mL} / \mathrm{h}$ and $240 \mathrm{~mL} / \mathrm{h}$ ) of the MQL system. Results showed that the grinding with MQL technique provided lower surface roughness values compared to conventional flood cooling, especially when machining under the intermediary cutting conditions. Also, with exception of $h_{\mathrm{eq}}$ of $0.09 \mu \mathrm{m}$, the MQL technique resulted in lower values of Rz parameter as compared to the conventional coolant technique, regardless of the flow rate tested.
\end{abstract}

Key words: Grinding, AISI P100 steel, MQL technique, equivalent chip thickness, surface roughness.

\section{Introduction}

Grinding is a machining process in which the material is removed by the action of hard abrasive grits bonded in a wheel with high cutting speed, therefore, it involves a high amount of energy per volume of material removed [1]. During the grinding process with conventional abrasives, it is estimated that approximately $85 \%$ of the heat generated is carried to the workpiece surface, which can cause surface damages such as microstructural changes, according to Malkin and Guo [1] and Diniz et al. [2]. Thus, it is essential to use coolant during the grinding process to reduce the friction between the abrasive

Corresponding author: Bruno Souza Abrão, PhD student, research field: grinding process. grits and the workpiece and the temperature in the cutting zone, according to Marinescu et al. [3]. Due to high costs and environmental impacts of the conventional cooling-lubrication technique (flood coolant), Tawakoli et al. [4] employed MQL (Minimum Quantity of Lubricant) which has emerged as an environmentally friendly alternative technique, allowing reducing the fluid flows used. The MQL technique consists in a minimal amount of fluid (frequently neat oil) pulverized in a flow of compressed air and directed toward the cutting zone.

The AISI P100 steel (VP100) is used in the manufacturing of molds for injection of plastics and non-chlorinated plastics. It is a low carbon steel grade developed with microalloying elements such as titanium and vanadium, which can be hardened at 
different cooling conditions of traditional quenching and tempering presenting homogeneous hardness from the surface to the core of the block. According to Rodrigues et al. [5] the low content of alloying elements in the VP100 steel, such as the low chromium content, contributes to its lower manufacturing costs, increasing its competitiveness in the market.

The grindability is an important point because the combination of the geometric and dimensional tolerances required for some of the molds and their functional components can generally be achieved by this abrasive process. According to Agostinho et al. [6], the roughness is defined as a microgeometric shape deviation formed by protrusions and valleys present on the surface of the part, and is commonly used to verify the quality (finish) of the molds produced, since any imperfection in the mold will be reproduced on the part to be manufactured. The surface roughness parameters are the main output variables to be measured because of the low cost of the conventional portable roughness meters which is very easy to handle compared to other apparatus used to evaluate machined component surfaces. In this way, the main roughness parameters employed are Ra and $\mathrm{Rz}$, in which the Ra represents the center line average distance of the roughness profile measured over a sampling length, while the parameter $\mathrm{Rz}$ represents the average distance between the 5 highest peaks and the 5 deepest valleys, within a sampling length. Fragoso et al. [7] performed the cylindrical grinding of the VP50 steel (38-42 HRC) with green silicon carbide grinding wheel, different feed rate values (0.25, 0.50 and $0.75 \mathrm{~mm} / \mathrm{min})$ and under different coolant delivery techniques. They reported that $\mathrm{Ra}$ parameter obtained results were between $0.5 \mu \mathrm{m}$ and $0.8 \mu \mathrm{m}$. Anjos et al. [8] used the same workpiece material and process as Fragoso et al. [7], but they used the white aluminum oxide grinding wheel $\left(\mathrm{Al}_{2} \mathrm{O}_{3}\right)$. It was observed that the grinding with the conventional cooling-lubrication technique and MQL technique, varying the equivalent chip thickness (from $0.02 \mu \mathrm{m}$ to $0.10 \mu \mathrm{m}$ ), resulted in Ra parameter values between 0.5 and $1.2 \mu \mathrm{m}$. Martínez-Mateo et al. [9] evaluated the surface damages, mainly as a function of the parameter $\mathrm{Ra}$, of molds during services. The hardness of the steel of the stationary part of the mold was $31 \mathrm{HRC}$, while the hardness of the movable part was approximately 53 HRC. It was observed that while the surface in contact with the movable mold half maintained the initial Ra value of $0.46 \mu \mathrm{m}$, the surface in contact with the stationary half of the mold showed an increase as the number of injected pieces increased, until reached $1.02 \mu \mathrm{m}$. Therefore, evaluating the surface roughness and texture of mold materials contributes to the sectors where they are used.

In this context, this paper evaluated the surface roughness and texture of the AISI P100 steel after grinding with cutting fluid applied by MQL technique using different flow rates and compared with the conventional coolant flow delivery (flood coolant).

\section{Experimental Procedure}

The machining tests were performed in a tangential surface grinding machine, P36 model, MELLO S.A manufacturer. The workpiece material was the AISI P100 steel (40 HRC) with the dimensions: $48.8 \mathrm{~mm}$ length $\times 20 \mathrm{~mm}$ width $\times 18 \mathrm{~mm}$ height. A conventional aluminum oxide grinding wheel (AA60K6V) with the dimensions of $303 \mathrm{~mm}$ external diameter $\times 25 \mathrm{~mm}$ width $\times 76 \mathrm{~mm}$ internal diameter, from Norton Abrasives manufacturer, was employed. The grinding wheel was dressed before each test with a dressing overlap ratio $\left(U_{d}\right)$ of 3 .

Two different cooling-lubrication techniques, the MQL and the conventional flood cooling, were tested. To the MQL cooling-lubrication technique, a vegetable based net oil, IORGABIO MQL SPECIAL specification, from IORGA OLEOS E PROTETIVOS INDUSTRIAIS LTDA, whereas an emulsion of the vegetable-based synthetic at concentration of $5 \%$, 
manufactured by TAPMATIC of BRASIL Ind. e Com. Ltda (ME-3 designation) was tested in conventional coolant technique (flood cooling). This fluid has a $\mathrm{pH}$ of 8.9 (basic characteristic). Fig. 1 shows the experimental set-up for the MQL technique and a summary of the machining parameters is shown in Table 1.

The surface roughness parameters $\mathrm{Ra}$ and $\mathrm{Rz}$ were measured after each test with the aid of a portable surface roughness tester, SJ201 P/M model, manufactured by Mitutoyo (Fig. 2a). A cut-off (sampling length) of $0.8 \mathrm{~mm}$ and measuring length of $5 \mathrm{~mm}$ were used. Measurements were performed in four different equidistant locations from each ground surface, as illustrated in Fig. 2b, and average of the readings considered for analysis. Examination of the machined surfaces was performed in an SEM (scanning electron microscope) to help in the analysis of the grinding mechanisms.

\section{Experimental Results}

\subsection{Surface Roughness}

Fig. 3 shows the surface roughness $(\mathrm{Ra})$ values after grinding the AISI P100 steel under different cutting conditions. It can be noted that, in general, the roughness values increase with increase of the equivalent chip thickness, regardless of the cooling-lubrication condition used. This is in agreement with the specific literature since an increase of $h_{\text {eq }}$ also increases the material removal, cutting forces, temperature and consequently leads to a poorer finishing, according to Bianchi et al. [10].

It can be also seen that machining with $h_{\text {eq }}$ up to $0.18 \mu \mathrm{m}$ and MQL technique with flow rate of 60 $\mathrm{mL} / \mathrm{h}$ provided lower surface finish values, while the MQL technique with $240 \mathrm{~mL} / \mathrm{h}$ outperformed the others after machining with $h_{\text {eq }}$ in excess of $0.09 \mu \mathrm{m}$. With exception of flow rate of $240 \mathrm{~mL} / \mathrm{h}$ and $h_{\text {eq }}$ up to 0.27 $\mu \mathrm{m}$, the results obtained with the all flow rates of MQL technique tested were similar or, in some cases, even lower than those obtained after machining with the conventional coolant technique.

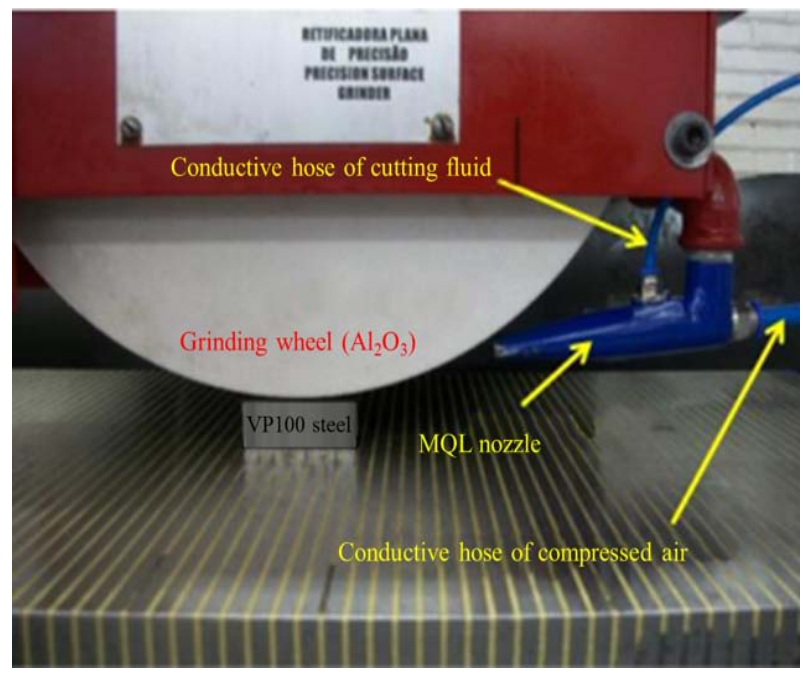

Fig. 1 Experimental set-up for grinding with MQL technique.

Table 1 Grinding parameters.

\begin{tabular}{ll}
\hline Cutting speed $(V s)(\mathrm{m} / \mathrm{s})$ & 38 \\
Equivalent chip thickness $\left(h_{\text {eq }}\right)(\mu \mathrm{m})$ & $0.09,0.18$ and 0.27 \\
Worktable speed $(V w)(\mathrm{m} / \mathrm{min})$ & 10 \\
MQL flow rates $(\mathrm{mL} / \mathrm{h})$ & 60,150 and 240 \\
Flood coolant flow rate $(\mathrm{mL} / \mathrm{h})$ & 545,000 \\
\hline
\end{tabular}
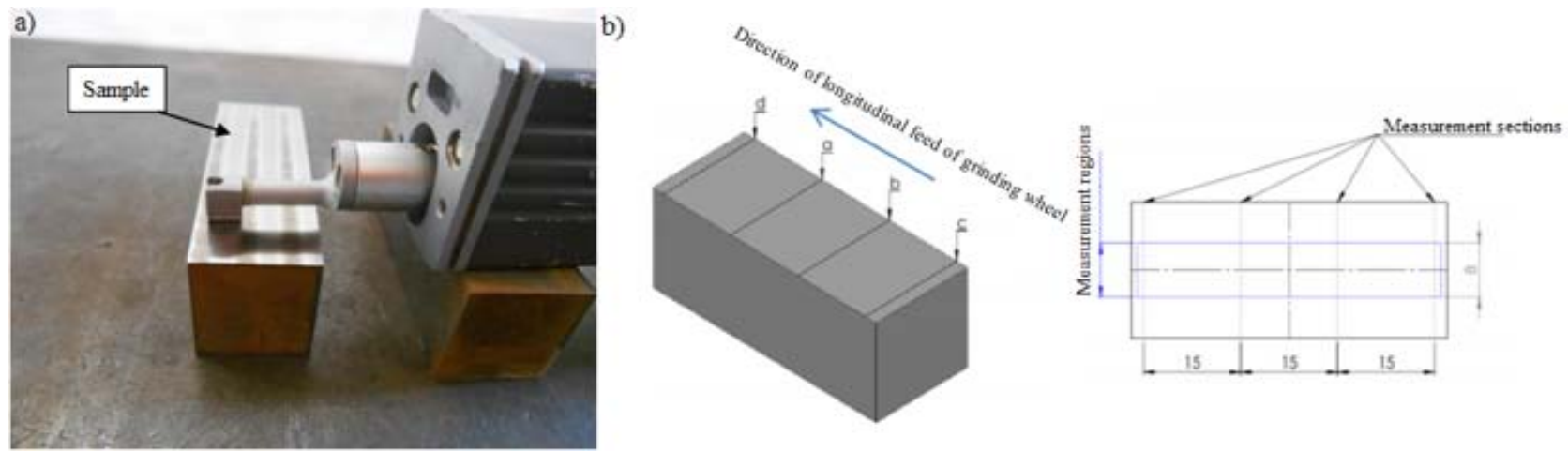

Fig. 2 (a) Surface finish measurement set up; (b) regions of the workpiece for measurements of surface roughness. 


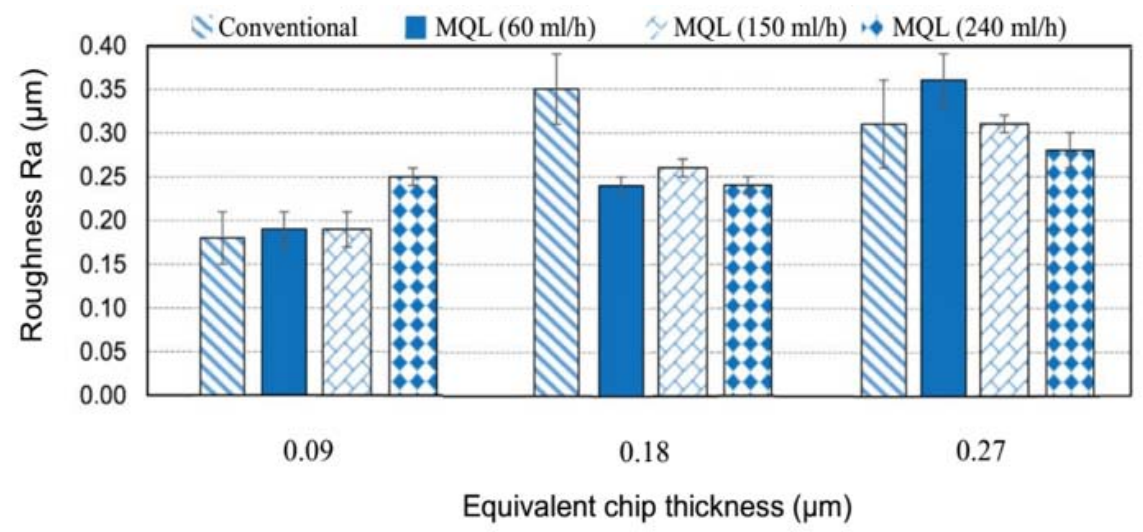

Fig. 3 Roughness Ra versus the equivalent chip thickness for the different cooling-lubrication conditions.

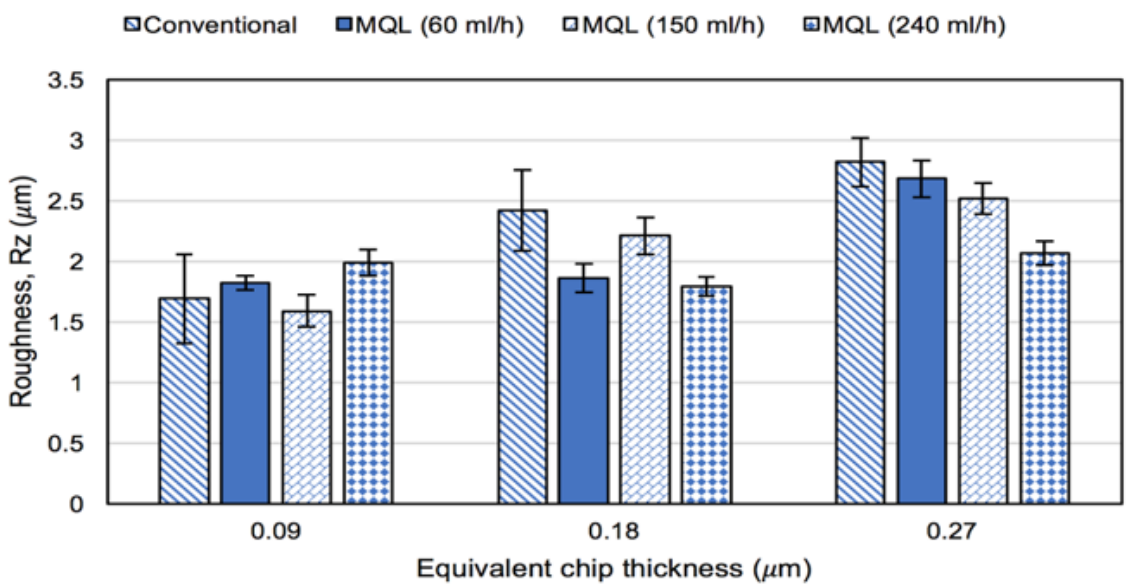

Fig. 4 Roughness Rz versus the equivalent chip thickness for the different cooling-lubrication conditions.

Fig. 4 showed the $\mathrm{Rz}$ surface roughness values obtained after grinding under the different cutting conditions. It can be seen that, similar to the behavior observed for the Ra parameter, the values of the $\mathrm{Rz}$ values increased with increase of the equivalent chip thickness, regardless of the cooling-lubrication condition employed.

In addition, machining with the MQL technique at a flow rate of $240 \mathrm{~mL} / \mathrm{h}$ outperformed the others in the most severe cutting conditions analyzed $\left(h_{\text {eq }}\right.$ of 0.18 $\mu \mathrm{m}$ and $0.27 \mu \mathrm{m}$ ), while machining with $h_{\mathrm{eq}}$ of 0.09 $\mu \mathrm{m}$, the results were similar for all conditions. With exception of $h_{\text {eq }}$ of $0.09 \mu \mathrm{m}$, the MQL technique with the all flow rates and $h_{\text {eq }}$ tested presented lower values of $\mathrm{Rz}$ parameter than the conventional technique. Ruzzi et al. [11] explain that this may be attributed to the fact that the MQL is able to break up the air barrier built around the spinning grinding wheel, while this is not possible in the conventional technique because of the low pressure applied to the coolant.

\subsection{SEM Images}

The SEM images of surfaces ground under different cooling-lubrication and cutting conditions are shown in Fig. 5. It can be seen from this figure that no adhered material was present on the ground surfaces under the conventional cooling-lubrication technique (Figs. 5a-5c), regardless of the $h_{\text {eq }}$ tested, thereby evidencing that the conventional technique (flood coolant) is effective on the removal of chips and maintaining clean the workpiece and the grinding wheel cutting surface. Moreover, the width of the grooves left by the grits of the abrasive wheel on the workpiece material surface was proportional to the radial depth of cut $\left(a_{e}\right)$ employed, as expected, since the higher the $a_{e}$, the higher is the area of the abrasive 


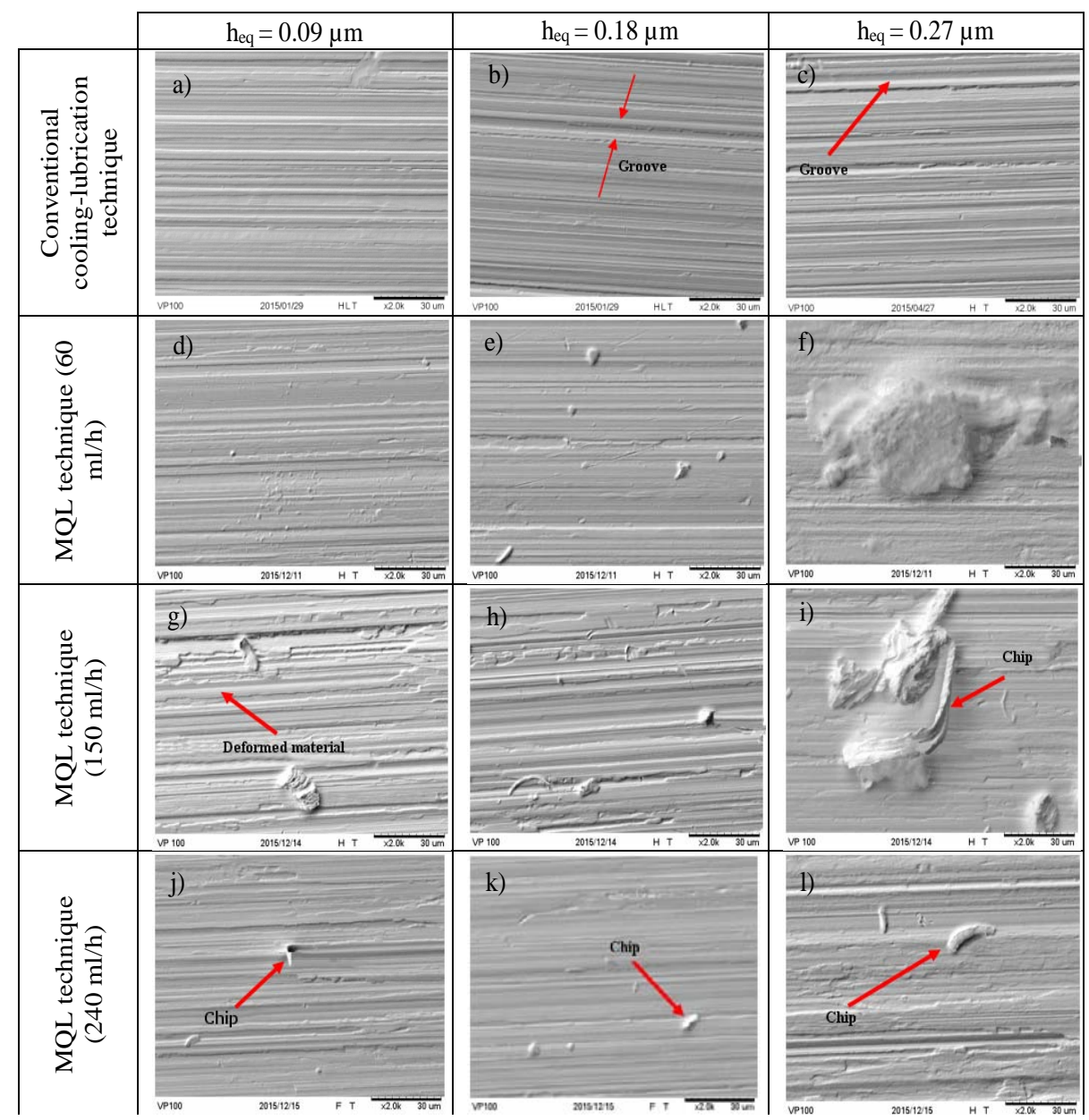

Fig. 5 SEM images of ground surfaces after machining with different cooling-lubrication techniques and cutting conditions.

grits in contact with the workpiece, according to Marinescu et al. [3]. In the surfaces ground with the MQL technique and flow rate of $60 \mathrm{~mL} / \mathrm{h}$ (Figs. 5d-5f) some debris can be seen (material of the workpiece deposited onto the machined surface by the movement of the grinding wheel and its pressure on the surface). It can be also seen that the texture of the workpiece surface worsened with increase of the ae, as expected. The feed marks presented on the surfaces after grinding with the conventional cooling-lubrication technique were more uniform than that presented after grinding with the MQL technique and flow rate of 60 $\mathrm{mL} / \mathrm{h}$. Increasing the flow rate of the oil of the MQL technique from 60 to $150 \mathrm{~mL} / \mathrm{h}$ (Figs. $5 g-5 \mathrm{i}$ ) and from 150 to $240 \mathrm{~mL} / \mathrm{h}$ (Figs. 5j-5l) in general generated ground surfaces with adhered materials, probably due to the chips that were carried out by the abrasive wheel and pressed against the workpiece material during the various turns of the abrasive wheel.

The section of the chips increased with the $h_{\mathrm{eq}}$, as expected. Oliveira et al. [12] showed in their experiments with CBN grinding wheel that the conventional technique is more efficient than the MQL to clean the cutting surface of the grinding wheel, thus, grinding with the MQL technique is more susceptible to clogging the pores of the abrasive wheel, which may explain the inferior performance of the MQL technique as compared to flood cooling tested in this work.

\section{Conclusions}

After the grinding tests, the following conclusions can be drawn from this work:

(1) The surface roughness, both $\mathrm{Ra}$ and $\mathrm{Rz}$ 
parameters, increased with increasing the equivalent chip thickness for all the cooling-lubrication conditions tested and the results obtained after machining with all flow rates of MQL technique were in general similar or, in some cases, even lower than those obtained for conventional coolant technique;

(2) The surfaces obtained after the grinding with the conventional cooling-lubrication technique were more uniform than those obtained with the MQL technique;

(3) The flow rate of MQL technique affected the surface finish and its performance was inferior compared to conventional coolant technique, probably due to its inefficiency of cleaning the chips from the grinding zone, which makes the abrasive wheel more susceptible to clogging phenomenon during grinding.

\section{Acknowledgements}

This study was financed in part by the Coordenação de Aperfeiçoamento de Pessoal de Nível Superior-Brasil (CAPES)—Finance Code 001. The authors are grateful too to the FAPEMIG and the Post Graduate Program of Mechanical Engineering of UFU for financial support. Authors are also grateful to Villares Metals (Brazil), and Saint Gobain Abrasives for supporting this work with workpiece material and wheel. One of authors thanks CNPq (PQ 2013 Project No. 308067/2013) for the research scholarship and FAPEMIG project process No. PPM-00265-13 for financial support. The authors are also thankful to ABCM for transferring the copyright of the article.

\section{References}

[1] Malkin, S., and Guo, C. 2008. Grinding Technology: Theory and Application of Machining with Abrasives. (2nd ed.). New York: Industrial Press, Inc., 372.

[2] Diniz, A. E., Marcondes, F. C., and Coppini, N. L. 2010. Tecnologia da usinagem dos materiais (7th ed.). São Paulo: Artliber Editora, 268.
[3] Marinescu, I. D., Rowe, W. B., Dimitrov, B., and Inasaki, I. 2004. Tribology of Abrasive Machining Processes (1st ed.). New York: Willian Andrew, 758.

[4] Tawakoli, T., Hadad, M. J., and Sadeghi, M. H. 2010. "Investigation on Minimum Quantity Lubricant-MQL Grinding of 100Cr6 Hardened Steel Using Different Abrasive and Coolant-Lubricant Types.” International Journal of Machine Tools \& Manufacture 50: 698-708.

[5] Rodrigues, J. R. P., Medeiros, M. A., Silva, F. C. S. E., Martins, K. C. R., Silva, M. B., and Machado, D. 2015. "Study of Machinability of VP 100 Steel with Different Levels of Titanium in End Milling Operations.” Acta Scientiarum. Technology 37: 41.

[6] Agostinho, O. L., Rodrigues, A. C. L., and Lirani, J. 1995. Tolerâncias, ajustes, desvios e análise de dimensões, edited by E. Blucher. São Paulo, 295.

[7] Fragoso, K. M., Umberto, D. R., Barili, I. C., Bianchi, E. C., Silva, R. B., Aguiar, P. R., and Mello, H. J. 2016. "Retificação cilíndrica do aço VP50 utilizando o rebolo de carbeto de silício verde com a técnica MQL.” Revista Matéria 21: 756-66.

[8] Anjos, M. C., Bianchi, E. C., Mello, H. J., Aguiar, P. R., Estambasse, E. C., and Hildebrandt, R. A. 2016. "Estudo experimental do uso de rebolos convencionais na usinagem do aço VP-50 utilizado na retificação cilíndrica, por meio de diferentes métodos de lubri-refrigeração.” Revista Matéria 21: 169-84.

[9] Martínez-Mateo, I., Carrión-Vilches, F. J., Sanes, J., and Bermúdez, M. D. 2010. "Surface Damage of Mold Steel and Its Influence on Surface Roughness of Injection Molded Plastic Parts.” Wear 271: 2512-6.

[10] Bianchi, E. C., Valarell, I. D., Fernandes, O. C., Mogami, O., Silva Jr, C. E., and Aguiar, P. R. 1997. “Análise do comportamento de rebolos convencionais na retificação de aços frágeis e dúcteis.” Journal of the Brazilian Society of Mechanical Sciences 19: 410-25.

[11] Ruzzi, R. De S., Belentani, R. De M., De Mello, H. J., Canarim, R. C., D’addona, D. M., Diniz, A. E., De Aguiar, P. R., and Bianchi, E. C. 2017. "MQL with Water in Cylindrical Plunge Grinding of Hardened Steels Using CBN Wheels, with and without Wheel Cleaning by Compressed Air.” The International Journal of Advanced Manufacturing Technology 90: 329-38.

[12] Oliveira, D. D. J., Guermandi, L. G., Bianchi, E. C., Diniz, A. E., Aguiar, P. R., and Canarim, R. C. 2012. "Improving Minimum Quantity Lubrication in CBN Grinding Using Compressed Air Wheel Cleaning." Journal of Materials Processing Technology 212: 2559-68. 